\section{O PAPEL DO ESPORTE NO PROJETO FORMADOR DAS ASSOCIAÇÕES CRISTÃS DE MOÇOS NO BRASIL (1903-1929)}

\author{
THE ROLE PLAYED BY SPORTS IN THE EDUCATIONAL PROJECT OF YOUNG \\ MEN'S CHRISTIAN ASSOCIATIONS IN BRAZIL (1903-1929)
}

EL PAPEL DEL DEPORTE EN EL PROYECTO FORMADOR DE LAS
ASOCIACIONES CRISTIANAS DE JÓVENES EN BRASIL (1903-1929)

Anderson Cunha Baía* , Andrea Moreno**

\begin{abstract}
Palavras chave:
Esportes.

História.

Associação.

Brasil.

Resumo: O presente estudo aborda o papel do esporte nas sedes da Associação Cristã de Moços (ACM) no Brasil. A Associação inseriu-se no Brasil no Rio de Janeiro (1893), Porto Alegre (1901) e São Paulo (1902). Com um projeto formador de contribuir na formação intelectual, moral-religiosa e física, percebe-se o esporte como uma prática que começa a ser indicada nas diferentes sedes no final da primeira década do século XX. Tivemos como propósito compreender o investimento das Associações Cristãs de Moços no Brasil, na construção de um ethos esportivo em um período circunscrito entre $1903 \mathrm{e}$ 1929. Mobilizamos as seguintes fontes: panfletos, cartilhas, relatórios, atas, estatutos e a Mocidade: Revista Mensal das Associações Christãs de Moços no Brasil. A Associação Cristã de Moços no Brasil, ao materializar a construção de um ethos esportivo por meio de suas ações, contribuiu para a inserção e presença do esporte no Brasil.
\end{abstract}

Keywords:

Sports.

History.

Association.

Brazil.

Palabras clave: Deportes.

Historia.

Asociación.

Brasil.

\begin{abstract}
The present study addresses the role played by sports at Young Men's Christian Association (YMCA) units in Brazil. The Association operated in Rio de Janeiro (1893), Porto Alegre (1901) and São Paulo (1902). With an educational project aimed at contributing to intellectual, moral-religious and physical formation, sports began to be applied in the different YMCA units in the late 1910s. Our purpose was to understand Brazilian YMCAs' investment in building a sporting ethos in 1903-1929. We used the following sources: leaflets, letters, reports, minutes of meetings and the magazine Mocidade: Revista Mensal das Associações Christãs de Moços no Brasil. By materializing a sporting ethos through its actions in Brazil, YMCAs contributed to bring sports to Brazil and to sustain their presence.
\end{abstract}

Resumen: El presente estudio aborda el papel del deporte en las sedes de la Asociación Cristiana de Jóvenes (ACM) en Brasil. La Asociación se insertó en Brasil en Rio de Janeiro (1893), Porto Alegre (1901) y São Paulo (1902). Con el proyecto inicial de contribuir en la formación intelectual, moral, religiosa y física, se percibe el deporte como una práctica que comienza a ser indicada en las diferentes sedes a fines de la primera década del siglo XX. Nuestro propósito fue comprender la inversión de las Asociaciones Cristianas de Jóvenes en Brasil en la construcción de un ethos deportivo en un período circunscrito entre 1903 y 1929. Movilizamos las siguientes fuentes: folletos, cartillas, informes, actas, estatutos y la revista mensual Mocidade, de la ACM en Brasil. La Asociación Cristiana de Jóvenes en Brasil, al materializar la construcción de un ethos deportivo a través de sus acciones, contribuyó con la inserción y la presencia del deporte en Brasil.
*Universidade Federal de Viçosa. Viçosa, MG, Brasil. E-mail: andersonbaia@yahoo.com.br

**Universidade Federal de Minas Gerais. Belo Horizonte, MG, Brasil. E-mail: andreafaeufmg@gmail.com

Recebido em: 19-07-2018 Aprovado em: 23-02-2019 Publicado em: 28-03-2019

DOI: https://doi.org/10.22456/1982-8918.84997 (c) (1) (8) Licence 


\section{INTRODUÇÃO}

A Associação Cristã de Moços (ACM) surgiu na Inglaterra, em 1844, por iniciativa de George Williams ${ }^{1}$. Nascido no sul da Inglaterra, em 1821, dedicou grande parte de sua vida ao trabalho acemista, falecendo em 1905. Em Londres, trabalhou em uma loja de tecidos, com elevada jornada de trabalho, o que foi decisivo para pensar na construção de uma instituição de ajuda mútua. Assim, nasceu a ACM, constituindo-se em um espaço de convívio para muitos jovens, animado "pelo espírito de fraternidade humana e cristã" (ASSOCIAÇÃO CRISTÃ DE MOÇOS, 2002, p. 5).

Essa Associação rompeu as fronteiras londrinas. Segundo Baía (2012), em 1851, na Europa, já havia 16 sedes distribuídas em outras regiões da Inglaterra, Escócia e Holanda. Nesse ano, também, são criadas as sedes de Montreal, no Canadá, e de Boston, nos Estados Unidos. Nesse país, com a criação da Comissão Internacional das Young Men's Christian Associations (YMCAs), em 1879, o movimento de expansão da Associação atinge outras regiões do mundo (MANSKE, 2006).

A presença de uma sede da instituição no Brasil foi parte desse movimento. Em 1887, foi encaminhado um pedido à Young Men's Christian Association, em Nova lorque, de autoria desconhecida, solicitando uma visita de membros da instituição para pesquisar a viabilidade em implantar uma sede no Brasil (SEGUI, 1998). O missionário norte-americano Chamberlain, que estava atuando no Brasil, em fins do ano de 1880, ao realizar uma palestra em escolas, nos Estados Unidos, também indicava a fertilidade do Brasil para receber uma sede da instituição. Em 1891, chega ao Brasil o norte-americano Myron Augusto Clark, com o propósito de constituir uma sede acemista no país (BAÍA, 2012)2. Implantou as sedes do Rio de Janeiro (1893), Porto Alegre (1901) e São Paulo (1902)³.

Sua missão estava centrada no desenvolvimento do caráter cristão e no desenvolvimento do "bem physico, intellectual, social e espiritual dos moços" (MODELO..., 1893, p. 2). Contudo, o projeto da Associação Cristã de Moços apresentava a religião como eixo condutor de suas ações (BAÍA, 2012). Para o missionário norte-americano Myron Clark:

Modestissima no seu principio, esta Associação foi pouco a pouco alargando o seu trabalho até abranger todos os ramos de trabalho hoje conhecidos como legítimos campos para a actividade dos moços christãos, mirando não sómente a conversão da mocidade, mas o seu bem-estar physico e intellectual (CLARK, 1898$, p. 46$)^{4}$.

A Associação trata de promover o bem-estar social, physico e intellectual da mocidade, tudo debaixo de um cunho religioso, combatendo o vicio em todas as suas fórmas, e apresentando Jesus Christo como o Moço bem formado por excellencia, o Modelo para a mocidade de hoje (CLARK, 1903, p. 13).

Se Myron Clark deu ênfase à dimensão religiosa nos primeiros anos de existência da Associação Cristã de Moços no Brasil, podemos perceber que em seu projeto já havia a

1 Segundo Baía (2012), o termo "Associação Cristã de Moços" (ACM) é conhecido como Young Men’s Christian Association (YMCA) em países de língua inglesa e recebe o nome de Asociación Cristiana de Jovenes (ACJ) em países de língua espanhola, exceto México e Espanha, que mantiveram YMCA.

2 Myron Clark nasceu e cresceu em uma família presbiteriana. Era um jovem de 25 anos, que atuava nas YMCAs e estava no último ano do "College", nos Estados Unidos (QUESITOS..., [19--], [s.p.]).

3 Nos primeiros anos de sua atuação no país, outras sedes foram criadas, mas não se consolidaram, extinguindo-se com o tempo (BAÍA, 2012).

4 Foi mantida a grafia original da fonte ao longo de todo o texto. 
necessidade de uma formação física (SEGUI, 1998). O esporte aparece como uma ação de um Departamento Físico no documento Em prol da Mocidade ${ }^{5}$, publicado em 1903, sendo, em 1907, incorporado no Estatuto da ACM carioca como mais uma "cultura física" da instituição. Ao percebermos a necessidade do esporte nos documentos oficiais da instituição a partir desse início do século $X X$, surgem algumas questões que nos orientam neste estudo, quais sejam: como o esporte se insere no projeto acemista? Como circula o discurso sobre o esporte na instituição e atinge as diferentes sedes brasileiras, contribuindo na criação de um ethos esportivo?

A partir dessas questões temos como propósito compreender o papel do esporte no projeto formador das Associações Cristãs de Moços no Brasil, no período de 1903 a 1929. Iniciamos este estudo em 1903 ancorados na inclusão do esporte como parte constituinte da obra de Clark, Em prol da Mocidade, indicando a sua inserção em um projeto de formação física da instituição. A finalização deste estudo em 1929 ao entender que esse ano marca o período final de implantação do projeto acemista no Brasil, iniciando o momento de consolidação ${ }^{6}$.

Para dar conta deste estudo, inspirados por Edward Hallet Carr, percebemos que os fatos não vêm às nossas mãos sem uma investigação, sem uma busca pelas fontes nos locais onde há maiores possibilidades de encontrá-las.

[...] os fatos não se assemelham aos peixes expostos na banca do comerciante. Assemelham-se aos peixes que nadam no oceano imenso e muitas vezes inacessiveis; o que o historiador apanhará depende em parte do acaso, mas sobretudo da região do oceano que tiver escolhido para a sua pesca e da isca de que se serve. Estes três fatores são, evidentemente, determinados pelo tipo de peixes que se propõe apanhar. Em geral, o historiador obterá o tipo de fatos que deseja encontrar (CARR, 1982 apud SCHAFF, 1991, p. 203).

Assim, localizamos documentos na Biblioteca Nacional, no Rio de Janeiro; na Federação Brasileira das ACMs, em São Paulo; e no Centro de Memória do Esporte (CEME), na Universidade Federal do Rio Grande do Sul (UFRGS), em Porto Alegre. Fizeram parte do corpus documental: panfletos, cartilhas, relatórios, atas e estatutos das diferentes sedes acemistas. Outra importante fonte para este estudo foi o periódico Mocidade: Revista Mensal das Associações Christãs de Moços no Brasil, que, sendo "órgão oficial das Associações Cristãs de Moços no Brasil", funcionou como um instrumento estratégico na circulação de objetivos, métodos, saberes e práticas que diziam da constituição do esporte na instituição.

De posse dos documentos em nossas análises, não se tratou, apenas, de dar voz a eles ou a um silêncio, mas transformar alguma coisa, que tinha sua posição e seu papel, em alguma outra coisa que funciona diferentemente (CERTEAU, 2006). Significou, portanto, compreender que as fontes, independentemente de sua natureza, variedade e valor, são apenas uma espécie de matéria prima a ser utilizada pelo historiador, sendo, portanto, uma condição necessária, mas não suficiente (LOPES, 1996).

\footnotetext{
5 Documento produzido por Myron Clark que apresenta a estrutura e as ações que deveriam constituir a formação acemista.

6 Na década de 1920, o movimento acemista no Brasil contava com quatro Associações implantadas, em fase de consolidação: Rio de Janeiro (1893), Porto Alegre (1901), São Paulo (1902) e Recife (1907). Ao se analisar as edições da revista Mocidade, encontra-se, a partir de 1924, uma ausência de informações referentes à sede de Recife, reforçada na VII Convenção das ACMs no Brasil, realizada em 1929, onde também não há sinais da presença da Associação Cristã de Moços de Recife. Dessa forma, mesmo sendo impreciso o fim das atividades da sede pernambucana, sua extinção revela um novo momento no projeto acemista brasileiro: fortalecia o investimento na consolidação das sedes existentes, abandonando, temporariamente, as iniciativas de implantação de novas sedes em outras regiões do Brasil. É esse novo momento que adotamos como marco final deste trabalho e que se define as sedes do Rio de Janeiro, Porto Alegre e São Paulo como as Associações priorizadas na análise acerca da criação do ethos esportivo (BAíA, 2012).
} 
No mais, ao trabalharmos com textos produzidos no interior e pela própria instituição, estivemos atentos à necessidade de procurar os interditos, as zonas opacas, os rastros ${ }^{7}$, como $^{2}$ propõe Ginzburg (2007). Assim, foi possível perceber a estrutura, as ações e as prescrições que caracterizaram a construção de um projeto acemista de formação para o jovem brasileiro, especialmente no que tange à contribuição das Associações Cristãs de Moços na constituição do esporte como prática a ser inserida no projeto de formação da instituição no Brasil.

\section{RIO DE JANEIRO, PORTO ALEGRE E SÃO PAULO: O ESPORTE NAS ACMS BRASILEIRAS}

Giddens (1991) afirma que os modos de vida produzidos pela modernidade nos separam dos tipos de vida tradicional sem precedentes. Sem desconsiderar as continuidades entre o tradicional e o moderno, as mudanças nos últimos três a quatro séculos foram de tal modo abrangentes em seus impactos que pouco conhecemos dessas alterações. Se concentrarmos nos anos finais do século XIX, Sevcenko (1992) aponta que profundas mudanças mundiais foram decisivas na construção de uma representação social marcada pelas inovações da Revolução Científico-Tecnológica, que, com o desenvolvimento do transporte, da eletricidade e do controle de doenças, possibilitou a introdução e apropriação de novos costumes, valores, hábitos, atitudes, comportamentos e também de novas práticas, dentre elas, algumas práticas corporais.

A Educação Física - constituída com a função de (con)formar o corpo no período moderno e nascida em meio a um processo de modernização e racionalização da vida - fez parte de um projeto de Brasil que gestava no final do século XIX. Diferentes práticas esportivas emergiram e se popularizaram no Rio de Janeiro, São Paulo e Porto Alegre, na transição do século XIX para o XX, como podemos perceber nos estudos de Melo $(1998,2000)^{8}$; Lucena (2000, 2001); Sevcenko (1992); Silva (2013); e Silva, Pereira e Mazo (2012). Dentro e fora das escolas, o esporte penetrou na vida do brasileiro e foi, pouco a pouco, instalando-se como parte do projeto de modernização pelo qual passavam algumas regiões do Brasil no final do século XIX e início do século XX.

Podemos ainda apontar a contribuição dos clubes esportivos nesse período em diferentes cidades brasileiras (LEMOS e GUEDES, 2008; SILVA, PEREIRA; MAZO, 2012). Segundo Elias e Dunning (1992), a formação de clubes, seja realizada por espectadores ou executantes, teve papel fundamental no desenvolvimento do esporte a nível mundial.

A Associação Cristã de Moços, a partir da matriz norte-americana, também contribuiu com essa difusão do esporte no Rio de Janeiro, em São Paulo e em Porto Alegre. A inserção dos esportes como ação acemista, organizada por um Departamento, foi tardia em relação à ginástica. Esta constava no Estatuto da sede carioca em 1903 e em 1904 na ACM gaúcha, porém ainda com o intuito de ser organizada, implantada e colocada a serviço dos associados.

Esta comissão deve primeiro promover a acquisição de apparelhos gymnasticos, simples e rudimentares a principio, para começar em escala pequena, e ir augmentando depois, pouco a pouco. Comprem-se altheres de pouco peso, que

7 Ao construir o "paradigma indiciário", Carlo Ginzburg (1989) parte da ideia central de que, se a realidade é opaca, existem zonas privilegiadas - indícios - que permitem decifrá-la.

8 Melo (1998) apresenta as sociedades ginásticas e as escolas protestantes, muitas delas de matriz norte-americana e inglesa, como instituições de difusão da ginástica e do esporte na sociedade carioca e em outras regiões do Brasil, como no Sul. Os imigrantes - franceses, alemães, ingleses - são compreendidos como grupos que contribuíram com a circulação de práticas corporais no Brasil, seja fundando associações, clubes ginásticos, organizando práticas corporais, possibilitando a circulação e influência múltipla dos diversos padrões culturais. 
bastarão para dar começo à obra. Para este fim abra-se uma subscripção entre os interessados, ou peça-se a algum amigo da Associação que faça donativo destes objectos (CLARK, 1903, p. 58).

Não encontramos evidências da inclusão do esporte no projeto formador da instituiç̧ão anterior à 1903. É no documento Em prol da mocidade, o mesmo em que constava a ginástica, que Myron Clark define a necessidade de um espaço no projeto formador das ACMs brasileiras com o intuito de possibilitar a prática de jogos atléticos.

A partir dessa indicação, percebemos o Estatuto da ACM do Rio de Janeiro, em 1907, oficializando a presença de jogos atléticos dentre as ações do Departamento Físico, como também aconteceu no Estatuto da mesma sede, em 1914, com a indicação da oferta de esportes:

Neste campo, terão logar todos os jogos athleticos, que a Commissão promove, especialmente em dias de feriados. Tennis, Foot-ball, corridas e muitos dos jogos mais communs e mais conhecidos, como: barra, carneiro, sella, pique, accusado, etc. Estes jogos athleticos terão 0 duplo valor de exercitar os associados e popularizar a Associação (CLARK, 1903, p.59).

Nas diferentes Associações, os "ensaios de foot-ball" e outros "jogos atheticos" iniciaram-se com frequências esparsas, geralmente por ocasião dos "pic-nics ou passeios campestres" promovidos em feriados e dias santos (ASSOCIAÇÃO CRISTÃ DE MOÇOS, 1910, p.12; ASSOCIAÇÃO CRISTÃ DE MOÇOS, 1911, p.10). Regras de "Volley Ball, traduzidas do guia Official Athlético e Internacional" foram divulgadas, assim como era incentivada a prática do "Base Ball, o jogo nacional americano, que está sendo muito apreciado especialmente no sul do Brazil" (ASSOCIAÇÃO CRISTÃ DE MOÇOS, 1911?) ${ }^{9}$.

Se, nos primeiros vinte anos do século XX, o esporte já se difundia pela sociedade brasileira em ritmo semelhante aos progressos da modernidade, no interior da Associação Cristã de Moços, a intensificação da propaganda em prol do esporte só aparece na revista Mocidade, na década de $1920^{10}$. Sevcenko (1998) mostra que as alterações culturais pelas quais passou a capital carioca no final do século XIX e início do século XX desencadearam uma febre esportiva que marcou o século $X X$ desde seus momentos iniciais. Porém, o salto qualitativo e quantitativo foi sentido somente após a Primeira Guerra Mundial, estendendo-se no decorrer dos anos 20 e 30.

Era a eletricidade passando para os corpos, imprimindo-lhes a compulsão do movimento, da ação, fosse espontânea, fosse mecânica, fosse em coordenação de massas. A Educação Física se torna obrigatória nas escolas, mas as pessoas se exercitam voluntariamente em academias, associações atléticas e na sua própria casa (SEVCENKO, 1998, p. 569).

A urbanização e o saneamento do Rio de Janeiro, que já existiam no início do século XIX, intensificam-se nos anos finais do século XIX e início do século XX. A cidade deveria expressar sinais dos novos tempos, dos novos intuitos econômicos, de uma suposta nova organização política, precisava ter uma nova aparência "civilizada" e "moderna" (MELO, 2000, p. 27). Para Sevcenko (1998, p. 571), o desenvolvimento dos esportes, na passagem do século,

9 Documento sem título e sem autoria, que apresenta o programa de atividades esportivas em uma sede da ACM. Há evidências que nos permitem inferir que seja do ano de 1911. Material acessado no arquivo da Federação Brasileira das ACMs, em São Paulo.

10 Não temos a pretensão de aprofundar a abordagem do movimento de modernização ocorrido nas cidades que compõem esse estudo. Porém, ressaltamos que o processo de modernização não se deu de forma tranquila, sem conflitos, conforme podemos encontrar em Cerasoli (2004), que, ao estudar a modernidade em São Paulo, caracterizou-a como um movimento plural, tenso, negociado, que envolveu diferentes sujeitos e projetos. 
apresentava como propósito adaptar os corpos e as mentes à demanda acelerada das novas tecnologias, assim, "como as metrópoles eram palco por excelência para o desempenho dos novos potenciais técnicos, nada mais natural que a reforma urbana incluísse também a reforma dos corpos e das mentes".

É no espírito de regeneração física, intelectual, social e moral-religiosa que a Associação carioca e as demais sedes juntaram-se às outras instituições públicas e privadas, fazendo circular no Brasil signos alinhados aos avanços da modernidade (BAIA, 2012).

Em São Paulo11, Sevcenko (1992) indica a existência de um boom esportivo na capital paulista, nas duas primeiras décadas do século XX.

Sob o epíteto genérico de 'diversões', toda uma nova série de hábitos, físicos, sensoriais mentais, são arduamente exercitados, concentradamente nos fins de semana, masarigorincorporados em doses metódicas como práticas indispensáveis da rotina cotidiana: esportes, danças, bebedeiras, tóxicos, estimulantes, competições, cinemas, shopping, desfiles de moda, chás, confeitarias, cervejarias, passeios, excursões, viagens, treinamentos, condicionamentos, corridas rasas, de fundo, de cavalos, de bicicletas, de motocicletas, de carros, de avião, tirosde-guerra, marchas, acampamentos, manobras, parques de diversões, boliches, patinação, passeios e corridas de barco, natação, saltos ornamentais, massagens, saunas, ginástica sueca, ginástica olímpica, ginástica coordenada com centenas de figurantes nos estádios, antes dos jogos e nas principais praças da cidade, toda semana. (SEVCENKO, 1992, p. 33).

Sevcenko (1992) afirma que muitos desses hábitos e práticas já existiam, pelo menos, desde o início do século XX. Nesse momento, São Paulo revelava uma nova sensibilidade que se ia definindo com uma cidade que crescia em escala fenomenal e que estava mergulhada em um processo modernizador.

São Paulo não era uma cidade nem de negros, nem de brancos e nem de mestiços; nem de estrangeiros e nem de brasileiros; nem americana, nem européia, nem nativa; nem era industrial, apesar do volume crescente das fábricas, nem entreposto agrícola, apesar da importância crucial do café; não era tropical, nem subtropical; não era ainda moderna, mas já não tinha mais passado (SEVCENKO, 1992, p. 31).

É nessa cidade que esses hábitos e práticas adquiriram um efeito coletivo, inserindo-se em uma rede de experiências do novo contexto social e cultural. Com isso, o esporte passa a ser fonte de uma nova identidade e de um novo estilo de vida. Seu público era chamado de "jovens" - uma expressão que passou a ter uma carga de prestígio - por ser adepto das práticas esportivas e de uma nova mentalidade, a da "ética do ativismo". Para Sevcenko (1992, p. 34): "[...] por trás disso tudo a filosofia é: ser jovem, desportista, vestir-se e saber dançar os ritmos da moda é ser 'moderno', a consagração máxima. O resto é decrepitude, impotência, passadismo e tem os dias contados".

Assim como a fórmula matricial 'American way of life' não descreve a realidade empírica de nenhuma comunidade específica, o mesmo tende a ocorrer com esse seu correlato, que também se poderia chamar de 'agitação Rio-São Paulo'. Não é preciso estar nos Estados Unidos para sentir e viver o 'American way of life', do mesmo modo como não é preciso estar no Rio de Janeiro ou em São Paulo para se imbuir neste 'Rio-São Paulo' [...] (SEVCENKO, 1998, p. 567).

11 Ao indicar a existência de semelhanças entre aspectos pontuais da modernização entre cidades - São Paulo, Rio de Janeiro e Porto Alegre -, não estamos afirmando que os processos foram idênticos. Cada região, com sua especificidade, com seus diferentes sujeitos e projetos, constituiu sua realidade a partir dos pressupostos da modernidade que circulavam no Brasil. 
Como aponta Sevcenko (1998), essa mutação cultural que atingiu o eixo Rio-São Paulo era sentida em outras partes do Brasil ${ }^{12}$. Porto Alegre, já nas primeiras décadas do século XX, apresentava um movimento esportivo.

Feix e Goellner (2008) apesentam o desenvolvimento industrial, as novas tecnologias, a mão de obra imigrante e as manifestações operárias como sendo indicativos de um despertar da cidade para o processo de civilização, rumo à modernização, que visava afastar a cidade da representação de cidade rural, que marcava a Porto Alegre dos fins do século XIX. Segundo Silva (2013), foi na transição do século XIX para o século XX que Porto Alegre apresentou sinais de progresso, com a extensão da rede elétrica, serviços de água e esgoto, surgimento de cafés, bondes elétricos, cinemas e automóveis, alinhando a cidade aos grandes centros urbanos mundiais.

Pesavento (1991) afirma que as duas primeiras décadas do século XX caracterizaram a construção de um novo estilo de vida em Porto Alegre, marcadamente público, coletivo, eufórico, encampando novas atitudes e práticas, como realçava Sevcenko ao se referir ao Rio de Janeiro e São Paulo.

Neste período as práticas corporais e esportivas despontavam como uma acessível opção de divertimento. Proliferavam, na cidade, os clubes recreativos, as agremiações, as federações, as regatas, as corridas de cavalo, as demonstrações ginásticas, as provas de ciclismo, os certames esportivos, os parques de lazer $e$ os campos de futebol, ao mesmo tempo em que se multiplicavam os espectadores e os participantes (FEIX; GOELLNER, 2008, p. 02).

Esse movimento esportivo na cidade de Porto Alegre teve uma contribuição do projeto de formação acemista, especialmente por meio da participação do gaúcho Frederico Guilherme Gaelzer. Esse, sócio da ACM de Porto Alegre na década de 1910, foi um dos enviados aos Estados Unidos para cursar Educação Física em instituição da YMCA.

Para Feix e Goellner (2008), dessa vivência de Frederico Gaelzer nos Estados Unidos surgiu o interesse de ver nascer, em Porto Alegre, espaços públicos destinados ao lazer. Em seu processo de formação nas Associações norte-americanas, Gaelzer observou as ações implementadas pelas diferentes sedes norte-americanas com propósitos de ofertar atividades de lazer para crianças e jovens, dentre elas: colônias de férias e playgrounds.

Ao retornar a Porto Alegre, Gaelzer investiu nesse processo de apoiar a prática esportiva. Afirmava que havia uma necessidade de se promover a generalização da atividade física, especialmente porque a educação estava atrelada à ideia de sobrevivência do mais forte.

Como a participação em algum ramo sportivo é um hábito como todos que adquirimos ao entrar na vida ativa, chegou-se a conclusão de que é necessário incutir no espírito do athleta, quando ele ainda mui criança, o hábito da actividade física. Dahi provem a necessidade urgente de introduzir em nossas escolas elementares a educação physica recreativa. Dessa forma incutiremos em nossa juventude 0 hábito de competição athletica. A criança por instinto corre, salta e em seus brinquedos faz contorções difíceis de imitar-se na gymnastica mais profissional. Ora o fim a que se deve almejar é conservar o corpo e o espírito jovem por toda a vida; pois só é velho quem se sente velho (ATLETISMO, 192?) ${ }^{13}$.

12 Dias (2013) nos propõe questionar o eixo Rio-São Paulo como centro irradiador do desenvolvimento do esporte na relação com o processo de modernização. Segundo ele, o papel do Rio de Janeiro, de São Paulo ou outro centro metropolitano na disseminação de esportes em um país como o Brasil, que apresenta uma grande diversidade cultural, aliada à extensão territorial, deve ser relativizado, se não questionado, uma vez que essas condições dificultam a identificação de um ponto único para a disseminação de esportes.

13 Jornal de nome desconhecido, com a matéria intitulada Atletismo - o sports nos Estados Unidos: alguns minutos de palestra com o jovem 
Envolvido pelas experiências norte-americanas e convencido da necessidade de proporcionar uma formação física aos rio-grandenses-do-sul, em 1927, Gaelzer foi o organizador da primeira praça de Educação Física e Esportes. Esse investimento na disseminação do esporte, inserindo o esporte no estilo de vida da população do Rio Grande do Sul, já se notava na Associação Cristã de Moços do Rio de Janeiro, desde o início da década de 1910.

\begin{abstract}
A Associação, conjuntamente com o Instituto Central do Povo, está presentemente em negociações com a Prefeitura para a cessão de um terreno na Quinta da Boa Vista, para servir de campo de Recreio, onde esperamos instalar aparelhos apropriados para sports, que serão realizados sob a direcção especial de um Diretor, vindo para este fim dos Estados Unidos (ASSOCIAÇÃO CRISTÃ DE MOÇOS, 1911, p. 10).
\end{abstract}

Também o Relatório institucional das ações realizadas pela ACM carioca nos anos de 1911 e 1912 apresenta a inauguração do Campo de Recreio no dia 12 de outubro de 1911, "mostrando-se installados os respectivos aparelhos" (ASSOCIAÇÃO CRISTÃ DE MOÇOS, 1912, p. 4). Todavia, não encontramos indícios de quais aparelhos e modalidades esportivas eram ofertados nesse novo espaço. A escassez de informações acerca dessa ação institucional nos órgãos de circulação acemistas sugere que a atuação da ACM carioca na disseminação do esporte, fora do espaço acemista, não se constituiu em ação prioritária no projeto acemista dessa sede. De todo modo, campos de recreio, tanto na ACM do Rio de Janeiro quanto na sede de Porto Alegre, fizeram parte de um projeto de formação física que não deveria ser restrito aos associados, mas ampliado para outros espaços sociais.

Devemos ressaltar, novamente, que Maurício Salassa, que havia sido enviado dos Estados Unidos em agosto de 1911, permaneceu na ACM carioca até seu regresso em 1912, sendo brevemente substituído por D. P. Cross, que, com poucos meses, transferiu o cargo para Sims. Além dessa inconstância de Diretores de Educação Física na ACM carioca, que poderia dificultar a construção de um projeto sólido de disseminação do esporte na Quinta da Boa Vista, não percebemos a presença de um missionário, com formação em Educação Física, especificamente para tratar das ações no Campo de Recreio, mas a tentativa de uma duplicidade de funções, em um momento em que a ACM carioca necessitava de maiores investimentos internos, devido à sua recente intensificação em prol das ações do Departamento Físico, observadas no início da década de 1910.

A atuação da Associação Cristã de Moços de Porto Alegre na disseminação do esporte, especificamente por meio da figura de Frederico Gaelzer, caracterizou-se diferente dos investimentos da sede carioca. Gaelzer contribuiu para a expansão do projeto acemista para fora da instituição, especialmente quando atuou no cargo de Inspetor de Educação Física da Secretaria de Educação de Porto Alegre, a partir de 1929, contribuindo com a organização de cursos intensivos de formação de Professores de Educação Física no Estado do Rio Grande do Sul.

Para Feix e Goellner (2008), as experiências adquiridas por Gaelzer nas suas viagens internacionais contribuíram para que pudesse defender suas ideias. Ele acreditava que a prática de atividades de lazer era um instrumento contra a delinquência e uma forma de qualificar a sociedade. Coincidentemente, suas propostas inseriram-se em um momento no qual a prática esportiva e de lazer estava em evidência naquele estado, especialmente pelo movimento da cultura física, que marcou as duas primeiras décadas do século XX e que vinculava a prática esportiva com o imaginário da modernidade.

rio-grandense F. G. Gaelzer. O original foi acessado no acervo do Centro de Memória do Esporte da ESEF/UFRGS. 
Assim, evidencia-se a aposta das três sedes acemistas na constituição de um ethos esportivo, salientando a importância das práticas esportivas na formação dos associados. Se, desde as origens das diferentes Associações Cristãs de Moços no Brasil, estava explícita a preocupação com a promoção do "bem physico" do sócio, a intensificação das ações do Departamento Físico somente foi percebida no início da década de 1920. A Associação Cristã de Moços influenciou e foi influenciada pelo clima cultural esportivo que permeava a sociedade brasileira desde os anos finais do século XIX.

\section{CONSIDERAÇÕES FINAIS}

As Associações Cristãs de Moços no Brasil foram espaços não escolares de formação. Organizadas para promover o "bem físico" e "intelectual" e a "moral religiosa" dos sócios, eram constituídas por um Departamento Físico responsável por diferentes ações. Como parte do trabalho da instituição no desenvolvimento da cultura física, o esporte aparece no início do século XX como mais um elemento formador.

O princípio de autonomia administrativa e organizacional entre diferentes sedes acemistas presente no ideário de Myron Clark não foi bem percebido quando se tratava do esporte. Sua presença em determinada sede rapidamente circulava nas outras unidades da instituição. A revista Mocidade, que circulava entre as diferentes sedes das ACMs, difundia as ações centrais da instituição, seja através de experiências exitosas em alguma sede, seja por meio de tradução de reportagens estrangeiras que apresentavam o esporte como uma prática alinhada ao contexto modernizador que se anunciava.

Por fim, o contato das sedes brasileiras com o projeto acemista norte-americano parece ter sido um fator importante na presença e difusão do esporte nas sedes brasileiras. Frederico Gaelzer e os próprios estrangeiros H. J. Sims, Myron Clark e Maurício Salassa foram personagens que atuaram intensamente na inserção e propagação do esporte nas ACMs brasileiras, contribuindo com o seu enraizamento. Alguns, como Gaelzer, extrapolaram suas ações para além da instituição, contribuindo com a presença do esporte em outros espaços sociais. Assim, a Associação Cristã de Moços no Brasil, ao atuar na difusão do esporte entre as diferentes sedes acemistas no início do século XX, contribuiu com a difusão do esporte no Brasil.

\section{REFERÊNCIAS}

ASSOCIAÇÃO CRISTÃ DE MOÇOS. 100 anos da Associação Cristã de Moços de São Paulo (1902-2002). São Paulo: Árvore da Terra, 2002.

ASSOCIAÇÃO CRISTÃ DE MOÇOS. Qual será o meu futuro? Rio de Janeiro, 1910.

ASSOCIAÇÃO CRISTÃ DE MOÇOS. Bom emprego para o Jovem Ambicioso. 1911.

ASSOCIAÇÃO CRISTÃ DE MOÇOS. [Sem título]. [1911?]

ASSOCIAÇÃO CRISTÃ DE MOÇOS. Signaes de Progresso: Relatório do Trabalho da Associação Cristã de Moços do Rio de Janeiro: Anos de 1911-1912. Rio de Janeiro, 1912. 
ATLETISMO - o sports nos Estados Unidos: alguns minutos de palestra com o jovem rio-grandense F. G. Gaelzer. In: Acervo do Centro de Memória do Esporte - UFRGS. Porto Alegre: [192?].

BAÍA, Anderson da Cunha. Associação Cristã de Moços no Brasil: um projeto de formação intelectual, moral e física (1890-1929). 2012. 214f. Belo Horizonte. Tese [Doutorado em Educação] - Faculdade de Educação, UFMG, Belo Horizonte, 2012.

BAIA, Anderson da Cunha; MORENO, Andrea. A construção do ethos esportivo nas Associações Cristãs de Moços brasileiras (1907-1929). In: CONGRESSO BRASILEIRO DE CIÊNCIAS DO ESPORTE, 19., 2015. Anais... Vitória: CBCE, 2015. Disponível em: http://congressos.cbce.org.br/ index.php/conbrace2015/6conice/paper/view/7286/3443. Acesso em: 11 mar. 2019.

CERASOLI, Josianne Francia. Modernização no Plural: obras públicas, tensões sociais e cidadania em São Paulo na passagem do século XIX para o XX. Tese [Doutorado em História] Instituto de Filosofia e Ciências Humanas, Universidade Estadual de Campinas, 2004.

CERTEAU, Michel de. A Escrita da História. Rio de Janeiro: Forense Universitária, 2006.

CLARK, Myron. Em prol da Mocidade: instruções sobre os trabalhos das Associações Cristãs de Moços. Rio de Janeiro: Casa editora presbiteriana, 1903.

CLARK, Myron Augusto. Associação Cristã de Moços do Rio de Janeiro: um esboço da sua história, dos seus objetivos, e dos seus métodos. Rio de Janeiro, Casa Publicadora Methodista, 1898. p. 46.

DIAS, Cleber. O esporte e a cidade na historiografia brasileira: uma revisão crítica. Dossiê: Uma história do esporte para um país esportivo. Revista Tempo, v. 19 n. 34, 2013. p.33-44.

ELIAS, Norbert; DUNNING, Eric. A busca da excitação. Lisboa: DIFEL, 1992.

FEIX, Eneida; GOELLNER, Silvana Vilodre. O florescimento dos espaços públicos de lazer e de recreação em Porto Alegre e o protagonismo de Frederico Guilherme Gaelzer. Licere, v.11, n.3, p.1-18, dez.2008.

GIDDENS, Anthony. As conseqüências da modernidade. São Paulo: Ed. Unesp, 1991.

GINZBURG, Carlo. Mitos, Emblemas e Sinais: Morfologia e história. 3.ed. São Paulo, Companhia das Letras, 1989.

GINZBURG, Carlo. 0 fio e os rastros: verdadeiro, falso, fictício. São Paulo: Companhia das Letras, 2007.

LEMOS, Rafael Medeiros; GUEDES, Raquel Cordeiro. A popularização do futebol no Rio de Janeiro durante a República Velha. Revista Historiador, v. 1, n. 1. p. 33-46, dez. 2008.

LOPES, Eliane Marta Teixeira. Métodos e fontes na História da Educação e Educação Física. In: ENCONTRO NACIONAL DE HISTÓRIA DO ESPORTE, LAZER E EDUCAÇÃO FÍSICA,4., 1996. Anais.... Belo Horizonte: UFMG, 1996.p. 35-49.

LUCENA, Ricardo de Figueiredo. 0 Esporte na Cidade. Campinas-SP: Autores Associados : CBCE, 2001.

LUCENA, Ricardo de Figueiredo. Rio de Janeiro: esporte, cidade e a construção da capital do Brasil. In: FERREIRA NETO (org.). Pesquisa Histórica na Educação Física. Aracruz: FACHA, 2000. p. 5-25. 
MANSKE, George Saliba. Um currículo para a produção de lideranças juvenis na Associação Cristã de Moços de Porto Alegre. 2006. 209f. Dissertação (Mestrado em Educação). Programa de Pós-graduação em Educação, Faculdade de Educação, UFRGS, Porto Alegre 2006.

MELO, Victor Andrade. A Educação Física nas escolas brasileiras do século XIX: Esporte ou Ginástica?. In: FERREIRA NETO (org.). Pesquisa Histórica na Educação Física. Aracruz: FACHA, 1998. p. 48-68.

MELO, Victor Andrade. O esporte e o projeto de "modernização" do Rio de Janeiro na transição dos séculos XIX-XX: as relações com as autoridades governamentais. In: FERREIRA NETO (org.). Pesquisa Histórica na Educação Física. Aracruz: FACHA, 2000. p.27-52.

MOCIDADE, revista mensal das Associacoes Christas de Mocos no Brasil. Rio de Janeiro: Associacoes Christas de Mocos no Brasil, 1898-1925.

MODELO dos Estatutos de uma Associação Cristã de Moços do Rio de Janeiro. New York/Rio de Janeiro, 1893.

PESAVENTO, Sandra Jatahy. Memória Porto Alegre: espaços e vivências. Porto Alegre: Editora da UFRGS, 1991.

QUESITOS e respostas sobre o trabalho da ACM no Brasil. [s.l.: s.n.], [19--].

SCHAFF, A. História e verdade. Lisboa: Martins Fontes, 1991.

SEGUI, Ary de Camargo. A Relação entre a Religião e a Educação Física na ACM de São

Paulo. 1998. 164f. Tese (Doutorado em Ciências da Religião) - Universidade Metodista de São Paulo, São Bernardo do Campo, 1998.

SEVCENKO, Nicolau. A Capital Irradiante: técnica, ritmos e ritos do Rio. In: SEVCENKO, Nicolau (org.). História da Vida Privada no Brasil. São Paulo: Companhia das Letras, 1998. v. 3.

SEVCENKO, Nicolau. Orféu Extático na Metrópole: São Paulo, sociedade e cultura nos frementes anos 20. São Paulo: Companhia das Letras, 1992.

SILVA, Carolina Fernandes; PEREIRA, Ester Liberato; MAZO, Janice Zarpellon. Clubes Sociais: práticas esportivas e identidades culturais. Licere, v.15, n.2, p. 1-21, Jun. 2012.

SILVA, Carolina Fernandes. Antes do Futebol... a ginástica, o remo e o ciclismo. In: GOELLNER, Silvana Vilodre; MÜLLER, Johanna Coelho Von (org.). Memórias do Esporte e do Lazer no Rio Grande do Sul. Porto Alegre: FUNDERG, 2013. p. 27-39.

Esse texto é resultado da pesquisa desenvolvido por Baía (2012) e tem uma versão inicial apresentada no Conbrace de 2015 (BAIA; MORENO, 2015). 